\title{
Analisis Kualitas Modul Matematika Kontekstual pada Topik Penyajian Data
}

\author{
Wengki Nopriadi ${ }^{1}$, Mirta Fera $^{2 *}$, Febrian $^{3}$ \\ ${ }^{123}$ Universitas Maritim Raja Ali Haji, Kota Tanjungpinang, 29111, Indonesia \\ Pengiriman: 06/April/2020; Diterima: 24/September/2020; Publikasi: 30/September/2020 \\ DOI: https://doi.org/10.31629/jg.v5i2.2159
}

\begin{abstract}
Abstrak
Penulisan artikel ini bertujuan menyajikan kajian kelayakan modul matematika kontekstual pada materi penyajian data pada siswa kelas VII paket B di PKBM Harapan Bangsa ditinjau dari aspek efektifitas, dan kepraktisannya. Jenis penelitian ini penelitian kualitatif dengan metode diskriptif. Pengumpulan data menggunakan soal post test untuk mendapatkan data kuantitatif dan angket respon siswa untuk mendapatkan data kualitatif. Hasil dari post test menunjukkan ketuntasan hasil belajar peserta didik adalah $80 \%$ atau sebanyak 8 orang peserta didik yang tuntas tuntas dari 10 siswa yang mengikuti post test. Dapat dinyatakan bahwa modul Matematika kontekstual pada materi penyajian data efektif. Hasil output person item map dari hasil angket respon siswa yang diolah dengan aplikasi winstep dengan pemodelan rasch diketahui bahwa 9 responden masuk kedalam kelompok praktis dan 1 responden masuk dalam kelompok tidak praktis, sehingga modul matematika kontekstual pada materi penyajian data bisa dinyatakan praktis. Dapat disimpulkan bahwa modul matematika kontekstual pada topik penyajian data untuk peserta didik kelas VII paket B di PKBM Harapan Bangsa layak untuk digunakan.
\end{abstract}

Kata kunci: kualitas; modul; kontekstual; penyajian data

\begin{abstract}
The writing of this article aims to present a feasibility study for a contextual mathematics module on the data presentation material for class VII students of package B at PKBM Harapan Bangsa in terms of effectiveness and practicality. This research is a qualitative type with descriptive method. Data collection uses post test questions to get quantitative data and student questionnaire responses to get qualitative data. Based on the results of the post test, it is known that the completeness of the learning outcomes of students is $80 \%$ or as many as 8 students who are thoroughly completed from 10 students who took the post test. It can be stated that the contextual Mathematics module on the data presentation material is effective. The results of the person item map output from the results of the student response questionnaire which was processed with the application of Winstep with Rasch modeling is known that 9 respondents belong to the practical group and 1 respondent belongs to the group impractical, so that the contextual Mathematics module on data presentation material can be declared practical. It can be concluded that the contextual mathematics module on the topic of data presentation for class VII students of Package B is appropriate to use.
\end{abstract}

Keywords: quality; module; contextual; data presentation

*Penulis Korespondensi

Email Address: mirtafera0901@umrah.ac.id

Handphone : +6285263302756 


\section{JURNAL GANTANG. September 2020; V(2): 171 - 177 \\ p-ISSN. 2503-0671 \\ e-ISSN. 2548-5547}

\section{Pendahuluan}

Pendidikan sebagai faktor utama untuk menghasilkan sumber daya manusia yang berkualitas. Sebagaimana telah tercantum dalam UU sistem pendidikan nasional No. 20 tahun 2003 BAB II pasal 3 yang menyatakan bahwa:

Pendidikan nasional berfungsi mengembangkan kemampuan dan membentuk watak serta peradaban bangsa yang bermartabat dalam rangka mencerdaskan kehidupan bangsa, bertujuan untuk berkembangnya potensi peserta didik agar menjadi manusia yang beriman dan bertakwa kepada Tuhan Yang Maha Esa, berakhlak mulia, sehat, berilmu, cakap, kreatif, mandiri, dan menjadi warga negara yang demokratis serta bertanggung jawab.

Untuk menghasilkan manusia yang berkualitas sebagaimana tujuan pendidikan nasional diatas maka diperlukan adanya kerja keras dari semua pelaku pendidikan. Sebagaimana yang diungkapkan oleh Indrajat (Muntiari, et al., 2013: 2). Bahwa dibutuhkan kerja keras semua pelaku pendidikan dalam peningkatkan dan pengembangkan potensi sumber daya manusia agar menjadi manusia yang terampil, berbudi pekerti, sehat jasmani rohani, kreatif, inovatif serta proaktif.

Tidak hanya jalur pendidikan formal, jalur pendidikan non formal juga merupakan jalur yang sangat berpengaruh agar tercapainya tujuan pendidikan nasioanl. Jalur pendidikan non formal adalah jalur pendidikan pada sistem pendidikan nasional yang bertujuan anatara lain untuk memenuhi kebutuhan belajar masyarakat yang tidak dapat dijangkau dan dipenuhi oleh jalur pendidikan formal. Jalur pendidikan non formal merupakan salah satu penunjang utama tercapainya tujuan dari pendidikan nasional, karena pada jalur pendidkan non formal banyak diajarkan berbagai ilmu dan pelajaran yang berguna bagi peserta didik untuk meningkatkan potensi-potensi yang ada pada peserta didik. Selain itu jalur pendidkan non formal khusunya pendidikan kesetaraan sangat menekankan pada konsep dari pendidikan nasional yaitu independency (kemandirian) dalam belajar. Kemandiriran dalam belajar adalah aktifitas belajar yang berlangsungnya dengan dorongan dan kemauan sendiri (Anzora, 2017:100).

Salah satu bagian dari jalur pendidikan nonformal yang sangat menekankan pada kemandirian peserta didik adalah pendidikan kesetaraan (program paket A setara SD/MI, paket B setara SMP/MTS dan paket C setara SMA/MA/SMK). Kemandiraan belajar peserta didik yang tinggi pada pendidikan kesetaraan disebabkan beberapa faktor diantaranya yaitu kurangnya pemahaman peserta didik dikarenakan usia yang berbeda-beda, kegiatan sehari-hari peserta didik yang padat, hingga waktu tatap muka yang bisa dikatakan sangat sedikit. sebagaimana tertera dalam Peraturan Menteri Pendidikan Nasional Republik Indonesia Nomor 3 Tahun 2008 Tentang Standar Proses Pendidikan Kesetaraan Program Paket A, Program Paket B, dan Program Paket C. Dalam Kegiatan pembelajaran sistem SKK dijelaskan bahwa:

1. Setiap peserta didik wajib mengikuti kegiatan pembelajaran baik dalam bentuk tatap muka, tutorial, maupun mandiri sesuai dengan jumlah SKK yang tercantum dalam Standar Isi Program Paket A, Program Paket B, dan Program Paket C.

2. Pengaturan kegiatan pembelajaran seperti tercantum pada butir 1 adalah tatap muka minimal 20\%, tutorial minimal $30 \%$, dan mandiri maksimal $50 \%$.

Kurangnya pemahaman peserta didik dikarenakan perbedaan usia, kegiatan sehari-hari peserta didik, hingga waktu tatap muka yang bisa dikatakan sangat sedikit menyebabkan pendidik harus mampu membuat suatu bahan ajar yang dapat menunjang peserta didik untuk bisa belajar secara mandiri serta bahan ajar tersebut harus mudah dipahami oleh peserta didik. Dengan demikian, perlu dikembangkan bahan ajar yang berkualitas, menarik serta sesuai dengan kebutuhan dan keadaan peserta didik demi tercapainya tujuan pembelajaran yang diinginkan.

Saah satu cara yang dapat dilakukan 
sekolah agar bisa mewujudkan kemandirian belajar siswa adalah dengan menggunakan bahan ajar yang layak dan sesuai dengan karakteristik peserta didik. Bahan ajar yang layak dan sesuai dengan karekteristik peserta didik akan mendorong mereka untuk belajar secara mandiri sesuai dengan kemampuannya masing-masing.

Modul merupakan salah satu bahan ajar yang dapat dikembangkan oleh guru dan digunakan oleh peserta didik sebagai penunjang dalam proses pembelajaran. Dalam Depdiknas (2008: 4) disebutkan bahwa modul merupakan salah satu bentuk bahan ajar yang dikemas secara utuh dan sistematis, didalamnya memuat seperangkat pengalaman belajar yang terencana dan didesain untuk membantu peserta didik menguasai tujuan belajar yang spesifik. Dhoruri (2010: 8) menyatakan bahwa dapat dilakukan penyesuaian terkait karakter peserta didik seperti sosial, budaya dan geografis pada pengembangan modul yang dibuat. Dengan menggunakan modul yang layak, guru dapat membantu mengatasi kesulitan ketika memahami, menjawab atau memecahkan masalah belajar yang dirasakan peserta didik. Hal ini juga sejalan dengan apa yang dikatakan Mulyasa (Budiono \& Susanto 2006:80) bahwa modul merupakan paket belajar mandiri yang meliputi serangkaian pengalaman belajar yang direncanakan serta dirancang secara sistematis untuk membantu peserta didik menguasai kompetensi belajar yang telah ditetapkan.

Dari penjelasan diatas dapat disimpulkan bahwa modul yang layak merupakan salah satu alternatif untuk membimbing peserta didik agar bisa belajar mandiri sesuai dengan konsep pendidikan nasioanal guna mencapai tujuan dari pendidikan nasional. Meskipun demikian, kualitas modul yang dikembangkan perlu diperiksa terkait kelayakannya. Untuk itu diperlukan adanya analisis kualitas modul dengan melihat kelayakan modul berdasarkan aspek keefektifan dan keperaktisan modul tersebut.

Analisis kualitas terkait bagaimana kelayakan modul matematika kontekstual pada topik penyajian data yang dilihat dari aspek keefektifan dan kepraktisannya dengan penyajian yang representatif diharapkan dapat memberikan informasi bagi pendidik ataupun peneliti. Sedangkan tujuan penelitian ini adalah untuk menyajikan kelayakan modul matematika kontekstual yang ditinjau dari aspek keefektifan dan kepraktisannya.

Kegiatan analisis kualitas terkait kepraktisan pada penelitian ini menggunakan analisis model Rasch yang relatif baru dan belum banyak digunakan terutama terkait dengan pengolahan data angket. Pemodelan Rasch mengubah data mentah dalam hal ini data angket yang bersifat ordinal menjadi data interval. Pengubahan data skor mentah menjadi data interval sehingga menghasilkan skala pengukuran yang linier,presisi dan mempunyai satuan (Sumintono dan Widhiarso, 2015). Sehingga analisis kualitas modul matematika kontekstual pada topik penyajian data dapat dideskripsikan.

\section{Metode Penelitian}

Penelitian ini mendeskrisikan kualitas modul modul matematika kontekstual pada materi penyajian data pada siswa kelas VII paket B di PKBM Harapan Bangsa ditinjau dari aspek efektifitas, dan kepraktisan. Sehingga pendekatan yang digunakan yaitu pendekatan kualitatif. Dimana jenis penelitian yang sesuai yaitu penelitian deskriptif dengan metode mendeskripsikan. Subjek penelitian ini adalah peserta didik kelas VII di PKBM Harapan Bangsa yang terdiri dari 10 orang siswa sebagai populasi penelitian yang semua anggota populasi dijadikan sebagai sampel. Berdasarkan hasil analisis karakteristik peserta didik di PKBM Harapan Bangsa peneliti dapatkan bahwa modul kontekstual cocok jika digunakan di sekolah tersebut.

Jenis data primer atau data langsung akan digunakan pada penelitian ini. Data ini mencakup data kualitatif dan kuantatif. Data kualitatif didapatkan dari hasil angket respon peserta didik. Data kuantitatif merupakan data yang didapatkan dari penilaian efektifitas modul yang berupa hasil dari tes hasil belajar (post test) 


\section{JURNAL GANTANG. September 2020; V(2): 171 - 177 \\ p-ISSN. 2503-0671 \\ e-ISSN. 2548-5547}

Untuk mengetahui nilai rata-rata kelas dan ketuntasan belajar guna melihat keefektifan modul, data tes hasil belajar dianalisis secara kuantitatif. Kriteria efektif modul matematika kontekstual apabila minimal tingkat ketuntasan yang dicapai dari tes hasil belajar pada post-test adalah kategori baik. Berdasarkan klasifikasi krititeria ketuntasan menurut Eko Putro Widyoko dalam Finka Astika (2014) dapat dilihat pada tabel 1 .

Tabel 1.

Kriteria ketuntasan tes hasil belajar

\begin{tabular}{cc}
\hline Presentase (\%) & Kategori \\
\hline$p>80$ & Sangat Baik \\
\hline $60<p \leq 80$ & Baik \\
\hline $40<p \leq 60$ & Cukup Baik \\
\hline $20<p \leq 40$ & Kurang Baik \\
\hline$p \leq 20$ & Tidak Baik \\
\hline
\end{tabular}

Pedoman penskoran dan penilaian posttest sebagai berikut :

1) Soal post-test terdiri dari 3 soal dengan total skor adalah 100.

2) Dari jumlah skor yang didapat selanjutnya dihitung nilai peserta didik dengan rumus nilai peserta $\operatorname{didik}(\mathrm{x})=$ jumlah skor

3) Hitung rata-rata Nilai post-test dengan cara $x=\frac{\sum \mathrm{x}}{n}$, dimana $\sum \mathrm{x}$ adalah jumlah nilai yang diperoleh dan $\mathrm{n}$ adalah banyak siswa.

4) Nilai post-testpeserta didik dibandingkan untuk menentukan peserta didik yang tuntas dan tidak tuntas. Nilai ketuntasan belajar individu (kriteria ketuntasan minimal) adalah 70 .

5) Ketuntasan tes hasil belajar (post-test) dihitung dengan cara:

Ketuntasan,

$p=\frac{\text { Jumlah siswa yang tuntas }}{\text { Jumlah siswa yang mengikuti tes }} \times 100 \%$

Angket respon siswa dianalisis secara kualitatif untuk melihat kecenderungan respon siswa terhadap keperaktisan modul. Modul dikatakan praktis apabila kecenderungan respon dari responden minimal berada pada kelompok praktis. Angket respon siswa berbentuk check-list dengan skala Likert yang terdiri dari 5 kategori, yaitu sangat setuju (SS), setuju (S), ragu-ragu (R), tidak setuju (TS), dan sangat tidak setuju (STS).

Tabel 2.

Pedoman skor penilaian

\begin{tabular}{lc}
\hline \multicolumn{1}{c}{ Kategori } & Skor \\
\hline Sangat Setuju (SS) & 5 \\
\hline Setuju (S) & 4 \\
\hline Ragu-ragu (R) & 3 \\
\hline Tidak Setuju (TS) & 2 \\
\hline Sangat Tidak Setuju (STS) & 1 \\
\hline Sumber $:$ Sugiyono $(2016: 65)$ &
\end{tabular}

Sumber : Sugiyono (2016:65)

Langkah-langkah dalam penentuan kepraktisan modul adalah sebagai berikut.

(1) Data yang diperoleh dari angket respon siswa merupakan data ordinal, sehingga di ubah menjadi data interval dengan menggunakan aplikasi Winstep dengan pemodelan Rasch.

(2) Kemudian data diolah menggunakan aplikasi Winstep dengan pemodelan Rasch untuk menganalis data respon siswa.

(3) Data yang telah diolah kemudian dianalis menggunakan menu person item map pada aplikasi Winstep.

(4) Langkah pertama yang dilakukan setelah data diolah oleh aplikasi Winstep adalah kita buka menu summary statistic untuk melihat nilai separation.

(5) Pengelompokkan person dan butir dapat diketahui melalui nilai separation.

(6) Nilai separation diolah dengan rumus person strata (Sumintono dan Widhiarso,2015:85):

$$
H=\frac{[(4 \times \text { SEPARATION })+1]}{3}
$$

(7) Nilai separation yang telah diolah akan menentukan banyaknya kelompok responden sesuai dengan kecendrungan respon yang diberikan.

(8) Hitung frekuensi responden pada person item map sesuai dengan pengelompokan yang didapat dari nilai separation.

(9) Tingkat keperaktisan modul ditentukan oleh kecenderungan respon dari responden yang dapat dilihat pada persen item map. 


\section{Hasil dan Pembahasan}

\section{Tes hasil belajar}

Data hasil post-test 10 orang peserta didik kelas VII PKBM dapat dilihat pada Tabel 3.

Tabel 3.

Hasil post test

\begin{tabular}{cccc}
\hline $\begin{array}{c}\text { Jumlah } \\
\text { Peserta } \\
\text { Didik }\end{array}$ & $\begin{array}{c}\text { Peserta } \\
\text { Didik } \\
\text { Yang } \\
\text { Tuntas }\end{array}$ & $\begin{array}{c}\text { Jumlah } \\
\text { Nilai }\end{array}$ & $\begin{array}{c}\text { Presentase } \\
\text { Ketuntasan }\end{array}$ \\
\hline 10 & 8 & 838 & $80 \%$ \\
\hline
\end{tabular}

Berdasarkan tabel 3 diketahui bahwa ketuntasan post-test siswa adalah $80 \%$ yang tuntas dari 10 siswa yang mengikuti post-test. Berdasarkan tabel kriteria ketuntasan tes hasil belajar pada tabel 1 termasuk kategori baik. Hal ini menujukan bahwa modul matematika kontekstual yang digunakan telah efektif yang memberikan hasil yang baik.

\section{Angket respon siswa}

Angket respon yang diisi oleh 10 orang peserta didik dan diolah dengan Winstep untuk melihat nilai separation peserta didik dengan hasil pengolahan pada Gambar 1 di bawah.

SUMMARY OF 10 MEASURED PerSON

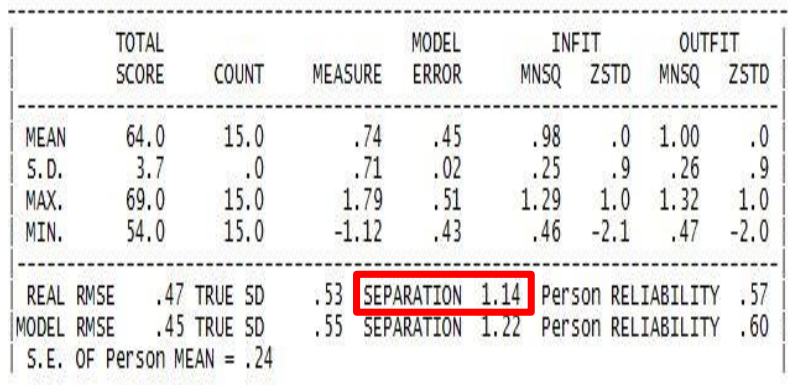

Gambar 1. Nilai separation angket respon peserta didik

Berdasarkan gambar 1 diketahui bahwa hasil indek separation person yaitu 1,14 . Nilai separation kemudian diolah dengan menggunakan rumus pemisahan strata untuk mementukan jumlah kelompok responden. Nilai strata responden dalam penelitian ini dapat dilihat dengan rumus pemisahan strata (Sumintono dan Widhiarso, 2015:85):

$$
H=\frac{[(4 \times S E P A R A T I O N)+1]}{3}
$$

Hasil yang didapat dengan perhitungan menggunakan rumus pemisahan strata dengan nilai separation 1.14 adalah 1,85 yang dibulatkan menjadi 2. Angka ini menunjukkan bahwa responden dibagi menjadi 2 kelompok keperaktisan modul, yaitu praktis dan tidak praktis.

Frekuensi dari masing masing kelompok dapat dilihat menggunakan Peta Wright menu person item map pada gambar 2, sebelah kiri memberikan informasi mengenai posisi pernyataan yang ditanggapi peserta didik yang menunjukkan respon kepraktisan atau praktikalitas dari modul dengan kategori praktis dan tidak praktis. Bagian sebelah kanan memuat informasi frekuensi penyebaran responden yang berada pada kelompok praktis dan tidak praktis:

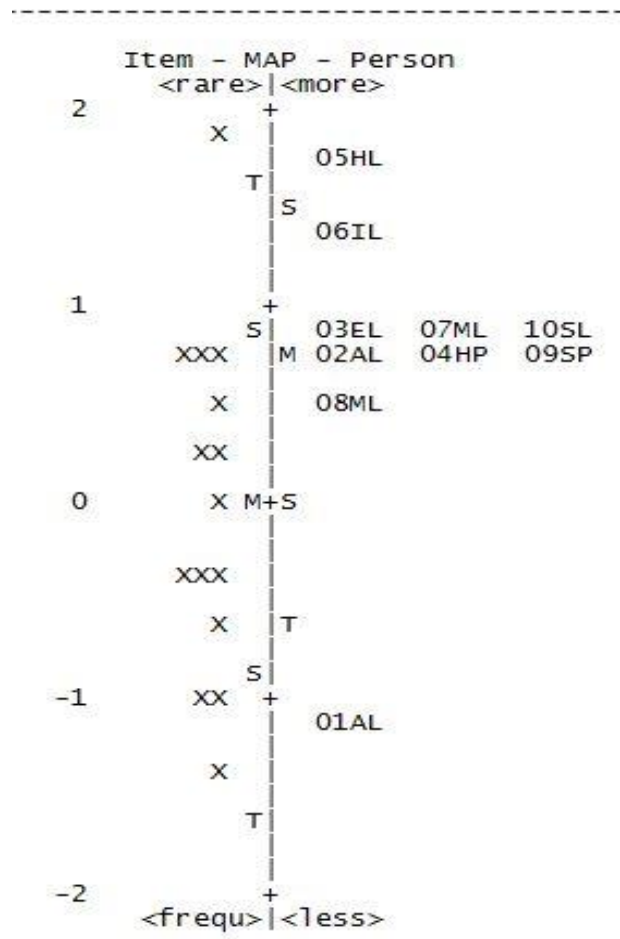

Gambar 2 Output item person map

Pengelompokan tingkat keperaktisan modul dan frekuensi dari dua kelompok disajikan pada tabel 4 .

Tabel 4.

Tingkat praktikalitas modul dengan person item map 
JURNAL GANTANG. September 2020; V(2): 171 - 177

p-ISSN. 2503-0671

e-ISSN. 2548-5547

\begin{tabular}{ccc}
\hline $\begin{array}{c}\text { Tingkat } \\
\text { Praktikalitas }\end{array}$ & $\begin{array}{c}\text { Person item } \\
\text { map }\end{array}$ & Frekuensi \\
\hline Kurang praktis & $-2<p<0$ & 1 \\
\hline Praktis & $0<p<2$ & 9 \\
\hline
\end{tabular}

Berdasarkan tingkat praktikalitas modul dengan person item map pada tabel 4 menunjukkan bahwa 9 responden dengan kode 08ML, 02AL, 04HP, 09SP, 10SL, 07ML, 03EL, 06IL dan 05HL masuk kedalam kelompok praktis dan 1 dengan kode 01AL yang masuk kedalam kelompok tidak peraktis. Dapat disimpulkan bahwa modul matematika kontekstual pada topik penyajian data termasuk kedalam kategori praktis dikarenakan dalam hal ini peserta didik dominan yaitu $90 \%$ berada dalam kelompok ini dan memberikan tanggapan praktis terhadap keperaktisan modul.

\section{Kesimpulan}

Setelah menganalisis kelayakan modul matematika kontekstual pada topik penyajian data berdasarkan aspek keefektifan dan kepraktisan didapatkan bahwa modul matematika kontekstual telah efektif untuk digunakan dalam pembelajaran matematika disekolah. Hal ini dibuktikan dari aspek keefektifan, yaitu tes hasil belajar (post test) yang menunjukkan bahwa $80 \%$ peserta didik tuntas dalam mengerjakan soal post-test. Modul matematika kontekstual telah praktis, yang berarti modul mudah jika digunakan dalam kegiatan pembelajaran disekolah. Hal ini dibuktikan dari hasil angket kepraktisan yang menunjukkan bahwa $90 \%$ peserta didik yang memberikan respon berada dalam kelompok praktis.

\section{Ucapan Terimakasih}

Terima kasih peneliti ucapkan kepada bapak Amirudin selaku kepala sekolah di PKBM Harapan Bangsa serta dosen pembimbing yang telah memberikan kesempatan dan bersedia meluangkan waktu untuk membimbing dalam penulisan artikel ini, serta seluruh pihak terkait yang telah berpartisipasi, memberikan masukan serta saran sehingga artikel ini dapat diselesaikan dengan baik dan tepat waktu

\section{Referensi}

Anzora. (2017). Analisis kemampuan siswa pada pembelajaran matematika dengan menerapkan teori belajar humanistik. Jurnal Gantang, 2(2), 99-103. https://doi.org/10.31629/jg.v2i2.200

Budiono, Eko., \& Hadi, Susanto. (2006). Penyusunan dan penggunaan modul pembelajaran berdasar kurikulum berbasis kompetensi sub pokok bahasan analisa kuantitatif untuk soal-soal dinamika sederhana pada kelas $\mathrm{X}$ semester I SMA. Jurnal Pendidikan Fisika Indonesia, 4 (2), 79-88 https://doi.org/10.15294/jpfi.v4i2.166

Depdiknas. (2008). Panduan pengembangan materi pembelajaran dan standar sarana dan prasarana sekolah menengah kejuruan madrasah aliyah SMA/ MA/ SMK/MAK. Jakarta: Depdiknas.

Dhoruri, A. (2010). Pembelajaran matematika dengan pendekatan matematika realistik (PMR). Makalah. Retrieved from http://staff.uny.ac.id/sites/default/files/tm p/Makalah\%20PMRI\%202010.pdf Juli 2018).

Astika, Finka Fitri (2014) Pengembangan modul pada materi matriks dengan pendekatan PMRI untuk siswa kelas X SMK. S1 Skripsi, UNY, Yogyakarta.

Muntiari, Ni Wayan, I. Made Candiasa, M. I. Kom, dan Nyoman Dantes. (2013). Pengaruh pendekatan pembelajaran matematika realistik terhadap prestasi belajar matematika ditinjau dari kemampuan numerik siswa kelas VIII SMP negeri 2 Amlapura. Jurnal Administrasi Pendidikan, 4(1), 1-11. https://doi.org/10.23887/japi.v4i1.1018.

Republik Indonesia. (2003). Undang-undang Republik Indonesia nomor 20 tahun 2003 tentang sistem pendidikan nasional. Jakarta: Sekretariat Negara.

Sugiono. (2016). Metodologi penelitian kualitatif kuantitatif dan kombinasi. Bandung: Alfabeta 
Nopriadi, Fera \& Febrian: Analisis kualitas Modul ...(18)

Sumintono, B., \& Widhiarso, W. (2015). Aplikasi pemodelan rasch pada assesment pendidikan. Bandung: Trim komunikata 
JURNAL GANTANG. September 2020; V(2): 171 - 177

p-ISSN. 2503-0671

e-ISSN. 2548-5547 